\title{
Tubulin carbamoylation
}

\section{Functional amino groups in microtubule assembly}

\author{
Wilfredo MELLADO, ${ }^{*}$ Juan C. SLEBE* and Ricardo B. MACCIONI*†‡ \\ *Instituto de Bioquímica, Facultad de Ciencias, Universidad A ustral de Chile, Valdivia, Chile, and \\ †Department of Biochemistry/Biophysics and Genetics, University of Colorado Health Sciences Center, \\ 4200 E. 9 th Avenue, B-121, Denver, CO 80262, U.S.A.
}

\section{(Received 28 October 1981/Accepted 2 March 1982)}

\begin{abstract}
The characteristics of the carbamoylation of pig brain tubulin were examined by using the modification conditions with cyanate described previously IMellado, Slebe \& Maccioni (1980) Biochem. Int. 1, 584-590l. The carbamoylation reaction resulted in an inhibition of microtubule assembly, which was dependent on the concentration of the modifying agent. This tubulin modification appears to inhibit the growth of microtubules. The presence of GTP did not protect tubulin against this inhibition. Electron microscopy showed a marked decrease in the number of tubules after carbamoylation, but no alterations were observed in the microtubule morphology. The incorporation of $\mathrm{KN}^{14} \mathrm{CO}$ into $\alpha$ - and $\beta$-subunits with similar kinetics was also shown, and the carbamoylated residues were identified as $\varepsilon$ - $N$-carbamoyl-lysine residues.
\end{abstract}

Microtubules are cylindrical structures of $24 \mathrm{~nm}$ diameter, formed by the assembly of tubulin $\alpha$ - and $\beta$-subunits, acidic polypeptides of mol.wt. 55000 (for reviews see Roberts \& Hyams, 1979; De Brabander \& De May, 1980; Timasheff \& Grisham, 1980).

The characteristics of the assembly process, as well as some approaches to its mechanism and the role of GTP, have been investigated previously (Gaskin et al., 1975; Maccioni \& Seeds, 1977a; Maccioni et al., 1981a; Margolis, 1981).

Studies of the function of specific residues in the tubulin molecule are needed for a better understanding of the molecular interactions involved in the assembly. Chemical modification with $p$-chloromercuribenzoate has been described where blockage of two thiol groups/molecule in the presence of glycerol inhibits the assembly (Kuriyama \& Sakai, 1974); modification of one thiol group/molecule by $N$-ethylmaleimide results in the complete loss of tubulin assembly (Mann et al., 1978). An inhibition of assembly after chemical modification of histidine residues in tubulin has also been shown (Lee et al., 1976), and an arginine residue was revealed to play an essential role in tubulin self-assembly (Maccioni et al., 1981b).

Abbreviation used. Mes, 4-morpholine-ethanesulphonic acid.

$\ddagger$ To whom correspondence and requests for reprints should be addressed, at Department of Biochemistry/ Biophysics and Genetics, University of Colorado Health Sciences Center, Denver, CO 80262, U.S.A.
Following a chemical modification approach we have reported that carbamoylation of tubulin resulted in an irreversible inactivation of its assembly ability (Mellado et al., 1980). In the present investigation we further analyse the characteristics of the reaction of tubulin with $\mathrm{KNCO}$, a compound that has been used as a probe to study the role of amino groups in the activity of some enzymes (Stark, 1965, 1972; Means \& Feeney, 1971). These studies show that the carbamoylation of highly reactive amino groups in both $\alpha$ - and $\beta$-subunits of tubulin leads to the inhibition of tubulin assembly.

\section{Materials and methods}

\section{Materials}

ATP, GTP, Mes and colchicine were obtained from Sigma Chemical Co.; recrystallized KNCO was from Mann Research Laboratories; the chromatographic gels were from Pharmacia Fine Chemicals; $\left[{ }^{3} \mathrm{H}\right]$ colchicine and $\mathrm{KN}^{14} \mathrm{CO}$ were purchased from The Radiochemical Centre; $\left[{ }^{3} \mathrm{H} \mid \mathrm{GTP}\right.$ was from New England Nuclear. All other chemicals were of analytical grade and used as supplied.

\section{Purification of tubulin}

Pig brain tubulin was prepared by three cycles of polymerization and depolymerization as described previously (Maccioni et al., 1981b). After the third polymerization step, the microtubular pellet was resuspended in $0.1 \mathrm{M}-\mathrm{Mes} / \mathrm{NaOH}$ buffer, $\mathrm{pH} 6.8$, and 
the solution was left for $15 \mathrm{~min}$ at $4^{\circ} \mathrm{C}$ and then centrifuged at $45000 \mathrm{~g}$ for $45 \mathrm{~min}$ to remove aggregates. This preparation was $90-95 \%$ tubulin, as assessed by analytical sodium dodecyl sulphate/ polyacrylamide-gel electrophoresis. Phosphocellulose-purified tubulin (Weingarten et al., 1975) was used in some experiments.

\section{Removal of guanine nucleotide bound to tubulin}

The solution obtained after the third depolymerization step was treated with charcoal in the presence of $1 \mathrm{~mm}$-EDTA as described by Maccioni $\&$ Seeds $(1977 a)$, to remove bound and remaining free nucleotide. Tubulin extracted under these conditions contained $1.0 \pm 0.1 \mathrm{~mol}$ of guanine nucleotide/mol of protein dimer.

\section{Polymerization assay}

The turbidity assay as described by Gaskin et al. (1974) was used to measure the tubulin polymerization. The assay was initiated by the addition of GTP (final concn. $1 \mathrm{~mm}$ ) to the tubulin sample $(1-2 \mathrm{mg} / \mathrm{ml})$ in assembly buffer $(0.1 \mathrm{M}-\mathrm{Mes} / \mathrm{NaOH}$ buffer, pH6.4, containing $1.1 \mathrm{mM}-\mathrm{MgCl}_{2}$ and $1.0 \mathrm{~mm}$-EGTA). The absorbance at $340 \mathrm{~nm}$ was recorded in a Gilford 2400 spectrophotometer during incubation of the tubulin solution at $32^{\circ} \mathrm{C}$. Samples assayed under identical conditions except for the omission of GTP were used as the blank. The sedimentation assay method of Johnson \& Borisy (1975) was also used in some experiments.

\section{Tubulin modification assay}

In some modification experiments (Figs. 1 and 2) cyanate was added to individual cuvettes containing tubulin (three-times-cycled or phosphocellulose-purified) at time zero (unless stated otherwise), the samples were induced to assemble in the presence of $1 \mathrm{mM}$-GTP and the assembly was monitored by turbidity or the sedimentation assay. Other experiments on the modification of tubulin by cyanate were performed by incubation of a protein solution $(8-12 \mathrm{mg} / \mathrm{ml})$ in $0.1 \mathrm{M}-\mathrm{Mes} / \mathrm{NaOH}$ buffer, $\mathrm{pH} 6.4$, containing $1.1 \mathrm{mM}-\mathrm{MgCl}_{2}$ and $1 \mathrm{mM}$-EGTA at $25^{\circ} \mathrm{C}$ in the presence of $\mathrm{KNCO}$ at the concentrations indicated. Samples were taken at various time intervals, diluted appropriately (as indicated in the Figures) in the same buffer and assayed for polymerization. In some experiments $\mathrm{KN}^{14} \mathrm{CO}$ was used to produce the radiolabelled carbamoylated derivative of tubulin. In control experiments tubulin was incubated with equivalent concentrations of $\mathrm{KCl}$ instead of KNCO.

\section{Colchicine binding}

Colchicine binding to modified and unmodified tubulin samples was assayed by the method of Weisenberg et al. (1968). Tubulin samples $(50 \mu \mathrm{l})$ were incubated at $37^{\circ} \mathrm{C}$ for $45 \mathrm{~min}$ with $24 \mu \mathrm{M}$ - $\left[{ }^{3} \mathrm{H}\right]$ colchicine (sp. radioactivity $4.3 \times 10^{5}$ c.p.m./ nmol). After the incubation, samples were filtered through two Whatman DE-81 DEAE-cellulose filter papers, and the filter papers were washed three times with $0.1 \mathrm{M}-\mathrm{Mes} / \mathrm{NaOH}$ buffer, $\mathrm{pH} 6.4$, containing $24 \mu \mathrm{M}$-colchicine and $5 \mathrm{mM}-\mathrm{MgCl}_{2}$. The filter papers were ground in $3 \mathrm{ml}$ of water, a 2,5-diphenyloxazole / 1,4-bis-(5-phenyloxazol-2-yl)benzene / toluene/Triton $\mathrm{X}-100$ scintillation mixture was added to the vials and the radioactivity was measured in a Tracor Analytic 6892 counter.

\section{Electrophoresis}

Tubulin samples obtained during a modification experiment in the presence of $50 \mathrm{mM}-\mathrm{KN}^{14} \mathrm{CO}$ $(0.48 \mu \mathrm{Ci} / \mu \mathrm{mol})$ were diluted appropriately in $62.5 \mathrm{~mm}$-Tris/ $\mathrm{HCl}$ buffer, pH6.8, containing $1 \mathrm{M}$ glycerol, $2 \%(\mathrm{w} / \mathrm{v})$ sodium dodecyl sulphate, $5 \%$ (v/v) 2-mercaptoethanol and $0.001 \%$ Bromophenol Blue and analysed by electrophoresis in sodium dodecyl sulphate/polyacrylamide slab or disc gels (7-8\% acrylamide) by the procedure of Laemmli (1970), with a constant current of $20 \mathrm{~mA} / \mathrm{gel}$.

Gels were stained with $0.1 \%$ Coomassie Blue in acetic $\mathrm{acid} / \mathrm{methanol} / \mathrm{water}(2: 5: 15$, by vol.) and destained in $10 \%(\mathrm{v} / \mathrm{v})$ acetic acid. Some gels were sliced into $2 \mathrm{~mm}$ pieces to determine the radioactivity associated with microtubular proteins. The gel slices were digested by incubation with $1 \mathrm{ml}$ of $30 \%(\mathrm{v} / \mathrm{v})$ in glass vials for $2 \mathrm{~h}$ at $60^{\circ} \mathrm{C}$, and the radioactivity was determined after addition of scintillation fluid.

\section{Electron microscopy}

Tubulin samples, treated or untreated with $\mathrm{KNCO}$, were incubated under polymerization conditions; $10 \mu \mathrm{l}$ samples were taken when the plateau of polymerization was reached and diluted 1:10 in a solution of $2 \%(\mathrm{v} / \mathrm{v})$ glutaraldehyde in assembly buffer. Drops of the fixed samples were placed on carbon-coated grids, stained with $1 \%(w / v)$ uranyl acetate and examined with a Philips EM 300 electron microscope.

\section{Identification of the $\mathrm{KN}^{14} \mathrm{CO}$-modified residues in} the tubulin molecule

A $0.3 \mathrm{ml}$ tubulin sample $(4 \mathrm{mg} / \mathrm{ml})$ was treated with $\mathrm{KN}^{14} \mathrm{CO}$ for $30 \mathrm{~min}$ at $25^{\circ} \mathrm{C}$. The modified sample was dialysed against water, freeze-dried and digested by incubation with $6 \mathrm{M}-\mathrm{HCl}$ for $24 \mathrm{~h}$ at $110^{\circ} \mathrm{C}$. After evaporation and resuspension in water, small portions of the hydrolysate were subjected to t.l.c. or to high-voltage electrophoresis in cellulose plates (Eastman Chromogram no. 6064). The t.l.c. was performed in a cellulose plate with butanol/acetic acid/water $(12: 3: 5$, by vol.) as solvent. One-dimensional electrophoresis was conducted for $25 \mathrm{~min}$ at $1000 \mathrm{~V}(24-30 \mathrm{~mA})$ in formic 
acid/acetic acid/water (10:11:379, by vol.), pH 1.9 . L-Homocitrulline was used as standard in both chromatography and electrophoresis. The amino acids from the hydrolysate as well as the standard were located after exposure of the plates to ninhydrin spray and heating at $35^{\circ} \mathrm{C}$ for $30-40 \mathrm{~min}$. The radioactivity of the chromatographed hydrolysate was determined after division of t.l.c. strips containing the sample into $1 \mathrm{~cm}$ pieces, resuspension in water and counting of the radioactivity with scintillation fluid. The same procedure was used to determine the radioactivity in the electrophoretic plates.

\section{GTP-binding assay}

The GTP-binding activity of tubulin was determined by the procedure of Allende et al. (1967) with Millipore HA $45 \mu \mathrm{m}$ filters.

\section{Results}

We have previously reported that the inactivation of tubulin polymerization by reaction with KNCO follows pseudo-first-order kinetics. This inactivation was shown to be associated with the carbamoylation of tubulin and the incorporation of $1 \mathrm{~mol}$ of $\mathrm{KN}^{14} \mathrm{CO} / \mathrm{mol}$ of tubulin heterodimer (Mellado et al., 1980). To obtain a better understanding of the tubulin carbamoylation reaction and the role of specific amino groups, studies were performed in the present study with a variety of modification conditions.

In order to study the effects of KNCO on the assembly kinetics, the reagent was added directly to the polymerization medium at two different time intervals (Fig. 1). Curve $A$ shows the action of the modifying agent when it was introduced in the polymerization medium at time zero, together with GTP. A significant increase in the lag period was observed, as well as a decrease in the initial velocity and in the extent of assembly as compared with the control experiment (curve $C$ ). The maximal extent of polymerization for the KNCO sample was $20 \%$ of the control at $8 \mathrm{~min}$; then the polymerization slowly decreased to approx. $12 \%$ of the control (curve $A$ compared with curve $C$ ). When $\mathrm{KNCO}$ was added $5 \mathrm{~min}$ after the polymerization started, turbidity continued to increase until $12 \mathrm{~min}$, but with diminished rate, and the maximal extent of assembly reached only $56 \%$ of the control value (curve $B$ ). The same effect of KNCO was observed when tubulin further purified by phosphocellulose chromatography was used in the experiment.

The effect of KNCO concentration on the extent of inhibition of assembly is shown in Fig. 2. In this experiment, increasing concentrations of the modifying reagent were added at time zero to separate cuvettes containing phosphocellulose-purified

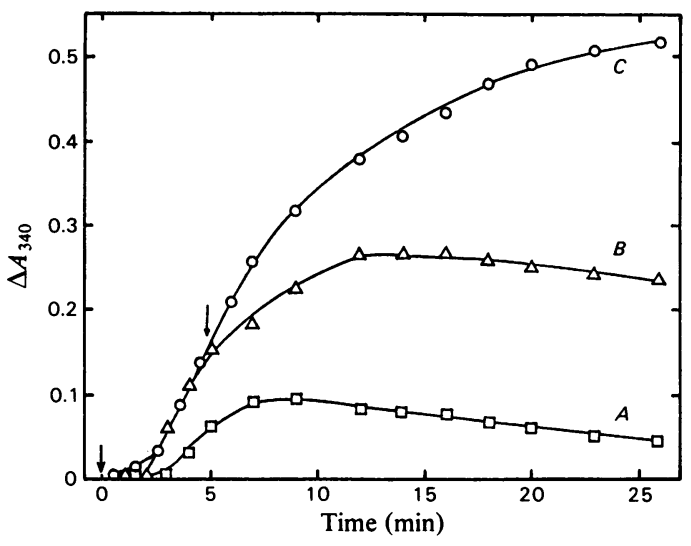

Fig. 1. Effect of $K N C O$ on the kinetics of tubulin polymerization

Tubulin samples, purified by three cycles of assembly-disassembly, at a final concentration of $1.4 \mathrm{mg} / \mathrm{ml}$, were assayed for polymerization at $32^{\circ} \mathrm{C}$ in the presence of $50 \mathrm{mM}-\mathrm{KCl}$ (curve $C, 0$ ) or in the presence of $50 \mathrm{mM}-\mathrm{KNCO}$ added to the polymerization medium at time zero (curve $A, \square$ ) and at 5 min after polymerization has started (curve $B, \Delta$ ). The $\Delta \boldsymbol{A}_{340}$ values represent the differences in the absorbance at $340 \mathrm{~nm}$ with respect to blanks incubated under the same conditions but without GTP.

tubulin, and the samples were induced to assemble in the presence of $1 \mathrm{mM}-\mathrm{GTP}$ and $10 \%(\mathrm{v} / \mathrm{v})$ dimethyl sulphoxide. The increase in $\mathrm{KNCO}$ concentration resulted in an increase in the inhibition of assembly, which reached a plateau at $\mathrm{KNCO}$ concentrations higher than $50 \mathrm{~mm}$. A similar relation between inhibition of the assembly and KNCO concentration was displayed when the experiment was performed with tubulin purified by the three-timespolymerization procedure, and after concentrated tubulin samples were incubated with increasing concentrations of $\mathrm{KNCO}$, diluted 10 -fold and assayed for assembly.

The effect of KNCO on the colchicine-binding activity of tubulin was also studied. Results summarized in Table 1 show that the incubation of tubulin with KNCO over a wide range of the reagent concentrations does not produce any significant change in the colchicine-binding activity. The results suggest that the amino acid residues modified by $\mathrm{KNCO}$, as well as other polar residues such as arginine (Maccioni et al., 1981b), are not responsible for the colchicine interaction with tubulin.

A mixing experiment was performed to assess whether the pool of modified heterodimers affects the assembly behaviour of native tubulin. The addition of KNCO-modified tubulin to a solution of 


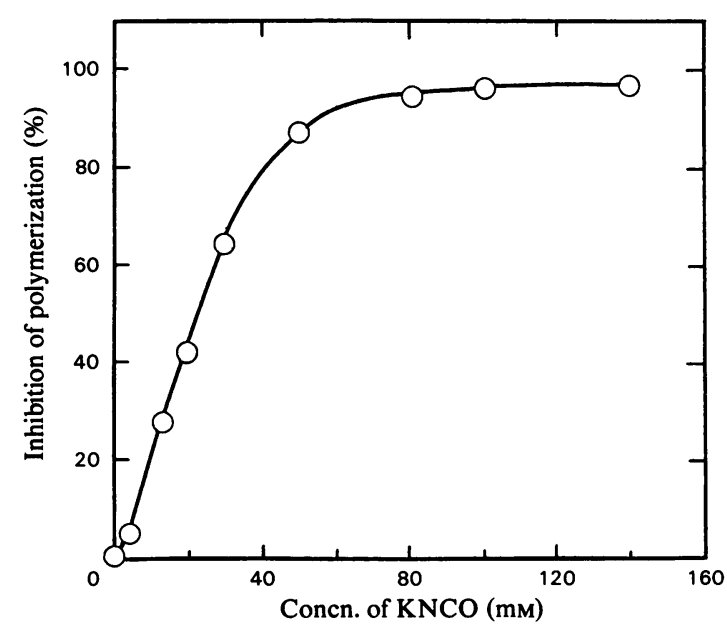

Fig. 2. Relation between the inhibition of tubulin polymerization and the KNCO concentration

Individual phosphocellulose-purified tubulin samples $(2 \mathrm{mg} / \mathrm{ml})$ were assayed for polymerization at $32^{\circ} \mathrm{C}$ in the presence of $1 \mathrm{mM}-$ GTP and $10 \%(\mathrm{v} / \mathrm{v})$ dimethyl sulphoxide and increasing concentrations of KNCO. The percentage inhibition was calculated by using the equation:

$$
\left(1-\frac{\Delta A_{340(\mathrm{KNCO})}}{\Delta A_{340(\mathrm{C})}}\right) \times 100
$$

where $\Delta A_{340(\mathrm{KNCO})}$ represents the maximum extent of polymerization in the presence of the different concentrations of $\mathrm{KNCO}$ and $\Delta A_{340(\mathrm{C})}$ is the extent of polymerization of the control sample. Similar results were obtained when the sedimentation assay was used to quantify microtubule assembly.

Table 1. Effect on the colchicine-binding activity of tubulin

Tubulin samples $(10 \mathrm{mg} / \mathrm{ml})$ were incubated for 15 min with $\mathrm{KNCO}$ at $25^{\circ} \mathrm{C} ; 10 \mu \mathrm{l}$ samples were removed, diluted $1: 5$ and assayed for $\left[{ }^{3} \mathrm{H}\right]$ colchicinebinding activity. Other conditions of colchicine binding are described in the Materials and methods section. Relative binding is expressed as $r_{\mathrm{b}} / r_{0}$, where $r_{b}$ is mol of $\left[{ }^{3} \mathrm{H}\right]$ colchicine bound $/ \mathrm{mol}$ of tubulin modified with KNCO and $r_{0}$ is mol of $\left[{ }^{3} \mathrm{H}\right]$ colchicine bound $/ \mathrm{mol}$ of tubulin incubated with $\mathrm{KCl}$ instead of KNCO (control: $0.57 \mathrm{~mol} / \mathrm{mol}$ of dimer).

$\begin{array}{cc}\text { Concn. of KNCO (mM) } & \text { Relative binding } \\ \left(r_{\mathrm{b}} / r_{0}\right) \\ 0 & 1.00 \\ 5 & 1.00 \\ 10 & 1.00 \\ 30 & 0.94 \\ 50 & 0.88 \\ 100 & 0.98 \\ 150 & 0.89 \\ 200 & 0.94\end{array}$

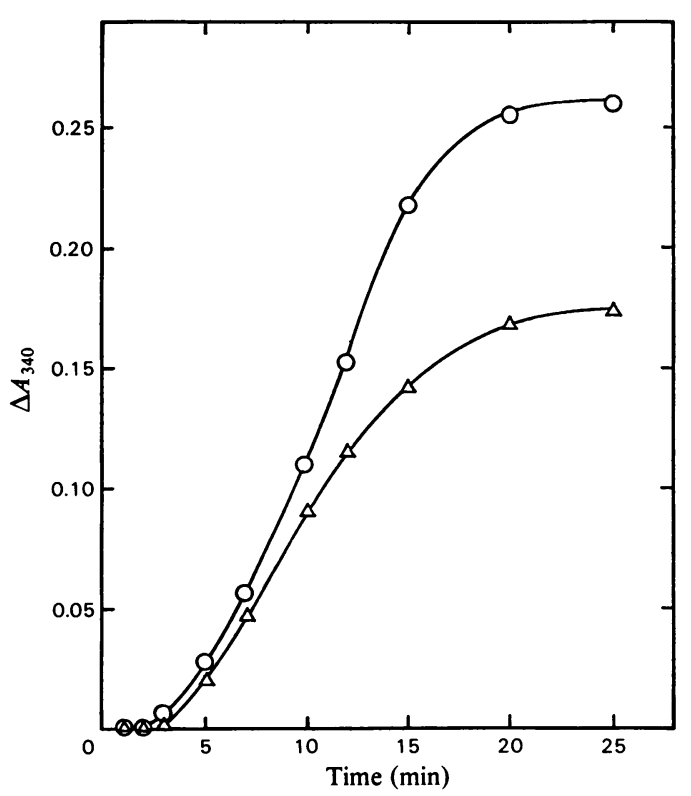

Fig. 3. Effect of the addition of KNCO-modified tubulin on the polymerization of unmodified tubulin

A $0.1 \mathrm{ml}$ sample of tubulin purified by the threetimes-polymerization procedure $(1 \mathrm{mg})$ was treated with $50 \mathrm{~mm}-\mathrm{KNCO}$ for $30 \mathrm{~min}$ at $25^{\circ} \mathrm{C}$, diluted $1: 8$ with assembly buffer, added to an unmodified tubulin sample $(2 \mathrm{mg})$ in a final volume of $1.0 \mathrm{ml}$ and assayed for polymerization $(\Delta)$. Another $1 \mathrm{mg}$ sample was treated with the same procedure except that $\mathrm{KNCO}$ was replaced by $\mathrm{KCl}$, added to $2 \mathrm{mg}$ of unmodified tubulin and assayed (O). A further control in which $1 \mathrm{mg}$ of tubulin was incubated with $\mathrm{KCl}$, added to $2 \mathrm{mg}$ of unmodified tubulin and assayed after the addition of KNCO (final concn. $5 \mathrm{~mm}$ ) showed the same results as the above control (O). Modified and unmodified samples added to unmodified tubulin and assayed in the absence of GTP served as blanks.

unmodified tubulin in the ratio $1: 2(\mathrm{w} / \mathrm{w})$ produced a decrease in the assembly to a value of $65 \%$ of that of the unmodified tubulin control (Fig. 3).

Electron-microscopy experiments were performed to examine the ultrastructural aspects of the assembly inhibition. A decreased number of tubules was seen in KNCO-modified tubulin preparations as compared with unmodified controls. However, no structural differences were found between these two preparations (Plates $1 a$ and $1 b$ ).

It has previously been shown that prolonged KNCO treatment of tubulin results in an irreversible assembly inactivation following apparent first-order kinetics (Mellado et al., 1980). The inactivation kinetics of tubulin by the $\mathrm{KNCO}$ 

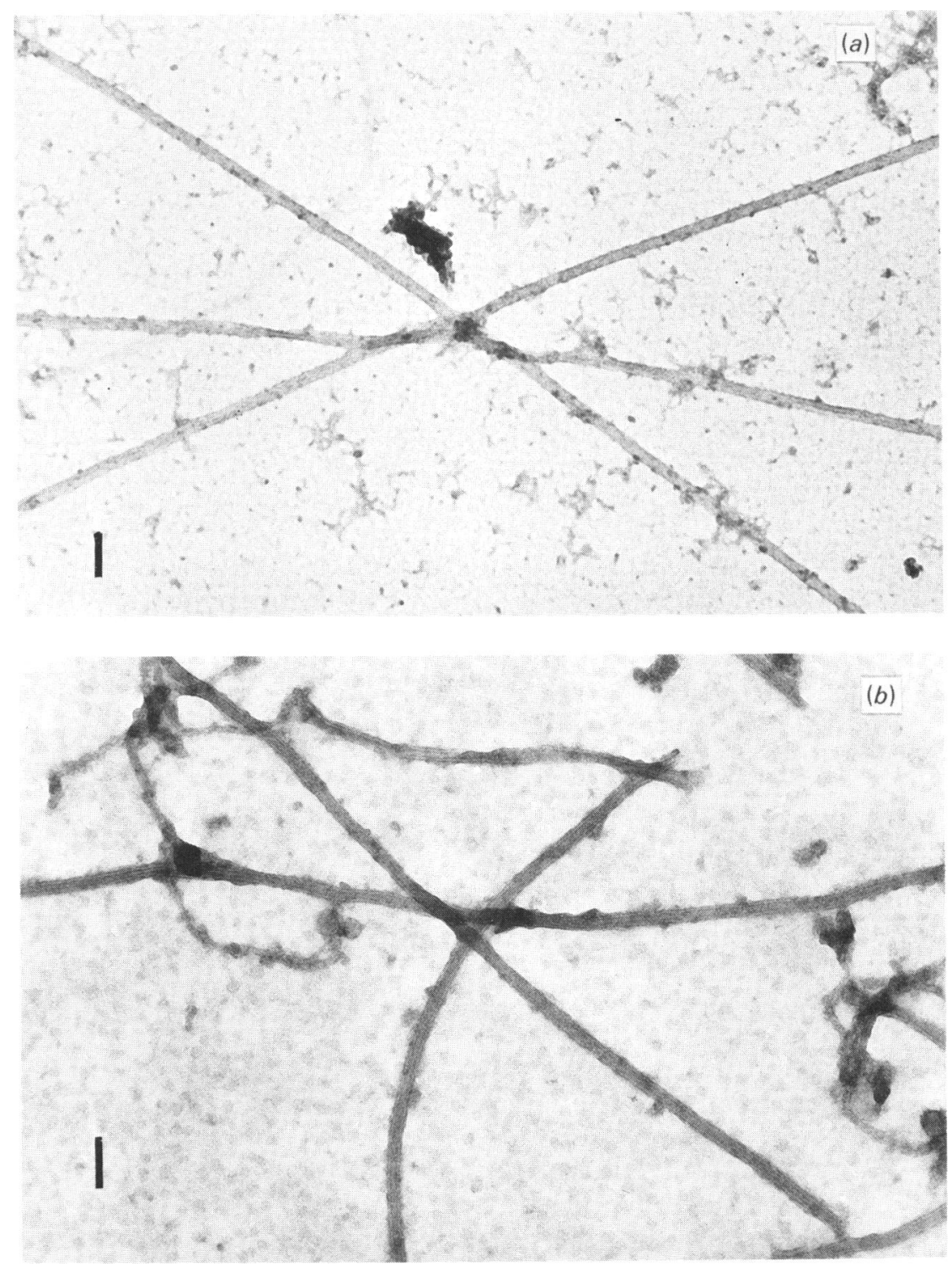

EXPLANATION OF PLATE 1

Electron microscopy of microtubules obtained from KNCO-modified and unmodified tubulin (a) Microtubules assembled from three-times-cycled tubulin $(12.5 \mathrm{mg} / \mathrm{ml})$ incubated for $10 \mathrm{~min}$ at $25^{\circ} \mathrm{C}$ with $50 \mathrm{mM}$ $\mathrm{KCl}$ in $0.1 \mathrm{M}-\mathrm{Mes} / \mathrm{NaOH}$ buffer, $\mathrm{pH} 6.4$, containing $1.1 \mathrm{mM}-\mathrm{MgCl}_{2}$ and $1 \mathrm{mM}-$ EGTA. (b) Microtubules assembled from tubulin incubated for $10 \mathrm{~min}$ at $25^{\circ} \mathrm{C}$ with $50 \mathrm{mM}-\mathrm{KNCO}$ in the same buffer. Other conditions are indicated in the Materials and methods section. The vertical bars represent $100 \mathrm{~nm}$. 
treatment in the presence of saturating concentrations of GTP (1-3 mM) were also analysed, but no significant protection by the nucleotide was observed. The assembly activity decreased to $24 \%$ of the control value ( $76 \%$ inhibition) after $25 \mathrm{~min}$ incubation with $50 \mathrm{~mm}-\mathrm{KNCO}$ in the presence of $2 \mathrm{mM}$-GTP as compared with a decrease to $18 \%$ of the control in the absence of nucleotide. In addition, the presence of the analogue [ $\beta \gamma$-imido]GTP $(2 \mathrm{mM})$ did not prevent the inactivation of tubulin by KNCO. However, preincubation of tubulin with $2 \mathrm{mM}$-GTP slightly diminished the loss of the $\left[{ }^{3} \mathrm{H}\right]$ GTP binding to tubulin caused by the KNCO modification (Table 2).

The loss of tubulin assembly is associated with the selective incorporation of $1 \mathrm{~mol}$ of $\mathrm{KN}^{14} \mathrm{CO} / \mathrm{mol}$ of tubulin dimer (Mellado et al., 1980). Therefore it was decided to determine in which subunit the amino acid residue(s) responsible for the carbamoylation reaction is located. After carbamoylation for $30 \mathrm{~min}$ with $50 \mathrm{~mm}-\mathrm{KNCO}$ and electrophoresis of the modified tubulin, radioactivity was found in both $\alpha$ and $\beta$-subunits of tubulin (Fig. 4). An incorporation of $0.5 \mathrm{~mol}$ of $\mathrm{KN}^{14} \mathrm{CO} / \mathrm{mol}$ of tubulin monomer was found in the $\alpha$-subunit, whereas the incorporation of the reagent into the $\beta$-subunit was $0.58 \mathrm{~mol} / \mathrm{mol}$ of monomer (Fig. 4).

Table 2. GTP binding to tubulin after carbamoylation in the presence and in the absence of the guanine nucleotide

Tubulin samples, purified by the three-times-polymerization procedure $(9 \mathrm{mg} / \mathrm{ml})$, were incubated at $25^{\circ} \mathrm{C}$ for $20 \mathrm{~min}$ either in the presence or in the absence of $3 \mathrm{~mm}-\mathrm{GTP}$ and $3 \mathrm{mM}-\mathrm{MgCl}_{2}$. Samples $(10 \mu \mathrm{l})$ were taken at the time intervals indicated, diluted 1:10 with $0.1 \mathrm{M}-\mathrm{Mes} / \mathrm{NaOH}$ buffer, $\mathrm{pH} 6.4$, containing $3 \mathrm{~mm}$-EDTA, treated with charcoal and assayed for GTP binding after the addition of $\mathrm{MgCl}_{2}$ (final concn. $1 \mathrm{mM}$ ). The concentration of $\left[{ }^{3} \mathrm{H}\right] \mathrm{GTP}$ in the binding assay mixture was $0.3 \mathrm{mM}(0.3 \mu \mathrm{Ci} / \mathrm{nmol})$. Relative $\left[{ }^{3} \mathrm{H}\right]$ GTP binding is the ratio of GTP binding of tubulin carbamoylated with $50 \mathrm{~mm}-\mathrm{KNCO}$ to GTP binding of tubulin incubated with $50 \mathrm{mM}-\mathrm{KCl}$ (control). The GTP binding of the control sample remained constant during the incubation: $0.35 \mathrm{~mol}$ of $\left[{ }^{3} \mathrm{H}\right] \mathrm{GTP} / \mathrm{mol}$ of tubulin dimer.

$\begin{array}{ccc}\text { Time } & \overbrace{\text { (min) }}^{\text {Relative }\left[{ }^{3} \mathrm{H}\right] \text { GTP binding }} \\ 0 & 1.00 & - \text { GTP } \\ 5 & 0.88 & 0.83 \\ 10 & 0.79 & 0.71 \\ 20 & 0.57 & 0.47 \\ 30 & 0.48 & 0.34\end{array}$

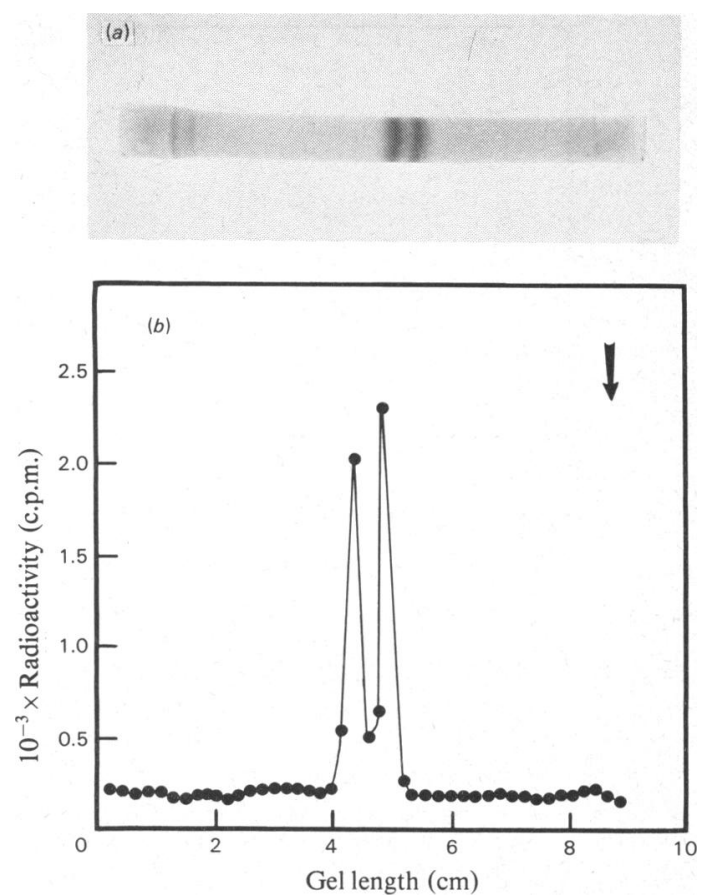

Fig. 4. Sodium dodecyl sulphate/polyacrylamide-gel electrophoresis of tubulin carbamoylated with $K N^{14} \mathrm{CO}$ A three-times-cycled tubulin sample $(12 \mathrm{mg} / \mathrm{ml})$ was treated with $50 \mathrm{~mm}-\mathrm{KN}^{14} \mathrm{CO}$ for $30 \mathrm{~min}$ at $25^{\circ} \mathrm{C}$. An $18 \mu \mathrm{l}$ sample was taken from the reaction medium, diluted 1:5 with a solution of $1 \%(w / v)$ sodium dodecyl sulphate, $3 \%(\mathrm{v} / \mathrm{v}) 2$-mercaptoethanol and $1 \mathrm{~mm}$-phenylmethanesulphonyl fluoride in $62.5 \mathrm{mM}$ Tris/ $\mathrm{HCl}$ buffer, $\mathrm{pH} 6.8$, boiled for $2 \mathrm{~min}$ and analysed by disc gel electrophoresis. (a) Stained polyacrylamide gel ( $8 \%$ acrylamide). (b) Radioactivity in the gel was determined after slicing the gel, digestion in $\mathrm{H}_{2} \mathrm{O}_{2}$ and scintillation counting. Other details are indicated in the Materials and methods section.

The kinetic profile for $\mathrm{KN}^{14} \mathrm{CO}$ incorporation into both subunits was determined from the radioactivity in $\alpha$ - and $\beta$-subunits after their electrophoretic separation from tubulin samples modified at different time intervals. Similar kinetics of incorporation were found for $\alpha$ - and $\beta$-subunits (Fig. 5).

The carbamoylated amino acid residues were identified by t.l.c. and high-voltage electrophoresis, after total digestion of the $\left[{ }^{14} \mathrm{C}\right]$ cyanate-modified tubulin derivative with $6 \mathrm{M}-\mathrm{HCl}$. It was found that the radioactive molecular species of the whole $\mathrm{HCl}$ hydrolysate co-migrated with homocitrulline, the $\varepsilon-N$-carbamoylated derivative of lysine. 


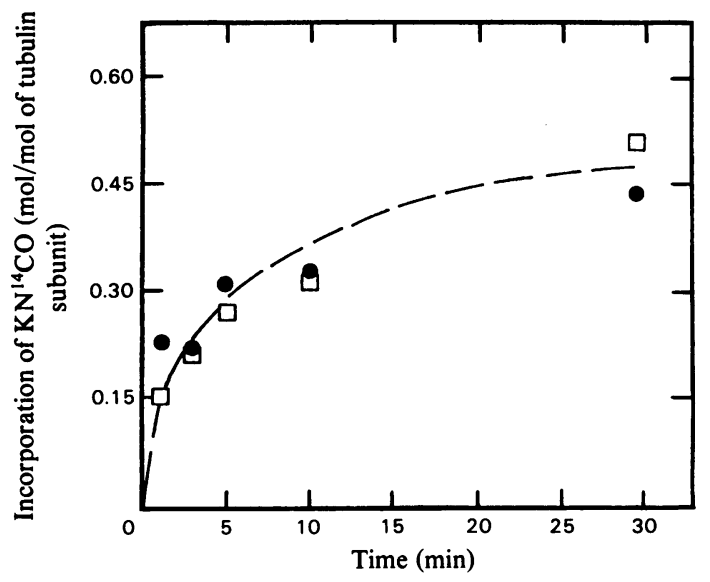

Fig. 5. Kinetics of incorporation of $K N^{14} \mathrm{CO}$ into $\alpha$ - and $\beta$-subunits of tubulin

Tubulin purified by the three-times-polymerization procedure $(12.5 \mathrm{mg} / \mathrm{ml})$ was treated with $50 \mathrm{~mm}$ $\mathrm{KN}^{14} \mathrm{CO}$, and $15 \mu \mathrm{l}$ samples were taken from the reaction medium at various time intervals and analysed as described in Fig. 4. The slices containing $\alpha$ - and $\beta$-subunits were obtained from the stained gels, digested and their radioactivities counted. $\alpha$-Subunit; $\square, \beta$-subunit.

\section{Discussion}

Cyanate is a protein-modifying agent that reacts with amino groups under neutral $\mathrm{pH}$ conditions. Possible modified residues and the mechanism have been discussed (Means \& Feeney, 1971; Stark, 1972). Tubulin modification by KNCO was shown to be an irreversible reaction involving amino groups of the protein (Mellado et al., 1980).

In a previous paper we showed that the treatment of tubulin with KNCO yields a carbamoylated derivative with decreased capacity of assembly (Mellado et al., 1980). The significant inhibition of assembly when the reagent was added $5 \mathrm{~min}$ after the assembly assay had started suggests that KNCO inhibits the elongation step in microtubule formation (Fig. 1, curve $B$ ). Electron microscopy also showed a decreased number of tubules and a higher proportion of shorter microtubules in preparations assembled in the presence of KNCO. This effect of $\mathrm{KNCO}$ is different from that of butanedione, an arginine-modifying reagent that inhibits assembly at the initiation step but not during the growing process (Maccioni et al., 1981b).

Because GTP is present in the polymerization assay mixture, a dynamic equilibrium produced by a polarized turnover of tubulin subunits should be expected, as described by the treadmilling model (Margolis \& Wilson, 1978; Margolis, 1981). How- ever, when KNCO was present the turbidity of the tubulin solution decreased slowly after polymerization plateaued for a short time interval (Fig. 1, curves $A$ and $B$ ). The loss of incorporation of free heterodimers at the growing pole probably reflects a tubulin modification that prevents the subunits from being incorporated into microtubules, with subunits released from tubules becoming exposed to cyanate modification.

The hypothesis that modified tubulin subunits have lost their ability to be incorporated into growing microtubules was also supported by the experiment of Fig. 3, where the addition of carbamoylated heterodimers to unmodified tubulin produced a decrease in the extent of assembly. If the modified heterodimers were incorporated into tubules, an increase in the extent of assembly with respect to untreated controls should be expected, unless they were incorporated at the growing pole and lowered the rate. The assembly decrease could also be a result of spurious tubulin-inactive protein interactions. A similar protein-concentrationdependent inactivation of the assembly was found when denatured tubulin was added to the assembly mix (R. B. Maccioni, unpublished work).

The electron microscopy showed that microtubules formed from modified tubulin are almost identical with those of the control experiment (Plate 1), although a decreased number of tubules was found in the modified preparations. This evidence is in agreement with the idea that in KNCO-treated preparations microtubules are formed from the population of unmodified tubulin heterodimers.

According to the studies by Stark $(1965,1972)$, the presence of unprotonated amino groups is a requirement for the protein carbamoylation reaction to occur. The high reactivity of tubulin amino groups to $\mathrm{KNCO}$ modification at the neutral $\mathrm{pH}$ conditions indicates that residues involved in the reaction should have an abnormally low $\mathrm{p} K$ value. A low $\mathrm{p} K$ value of the tubulin reactive amino groups suggests a hydrophobic or slightly positively charged microenvironment for the residues. The presence of low-pK amino groups of lysine residues has been reported in acetate decarboxylase (Schmidt \& Westheimer, 1971), aspartate aminotransferase (Slebe \& Martinez-Carrion, 1976) and glutamate dehydrogenase (Veronese et al., 1972). Similar characteristics have been described for the terminal amino group of myoglobins (Garner et al., 1973).

The irreversible incorporation of $\mathrm{KN}^{14} \mathrm{CO}$ into $\alpha$ and $\beta$-subunits in equivalent proportions shows that both monomers have reactive amino groups susceptible to modification by cyanate. Furthermore, the kinetics of incorporation of $\mathrm{KN}^{14} \mathrm{CO}$ to both subunits indicate the residues have very similar reactivities, thus suggesting similarities in the microenvironment around the residues. This type of 
labelling (approx. $0.5 \mathrm{~mol}$ of cyanate/mol of tubulin subunit) may be explained by similar reactivity of lysine residues of both $\alpha$ - and $\beta$-subunits of tubulin, with a conformational change occurring to mask the residue in the other subunit once one residue is modified; however, another possibility could be an incomplete labelling of the subunits. Galella \& Smith (1979), using bifunctional reagents, concluded the presence of free amino groups in both $\alpha$ - and $\beta$-subunits of tubulin. The finding of $\varepsilon-N$-carbamoylated lysine residues in both $\alpha$ - and $\beta$-subunits of tubulin is in agreement with the results obtained by Maccioni \& Seeds (1977b), where labelling with the analogue $2^{\prime}, 3^{\prime}$-dialdehydo-GTP (approx. $1 \mathrm{~mol}$ of analogue/mol of tubulin dimer) formed covalent derivatives with $\alpha$ - and $\beta$-subunits of tubulin. Additional evidence supporting the existence of reactive amino groups in both tubulin subunits comes from studies by Brodie et al. (1980), with nitrosourea derivatives, and by Mann et al. (1978), who showed that incorporation of $N$-ethylmaleimide into $\alpha$ - and $\beta$-subunits was related to the loss of assembly. Furthermore GTP analogues, used as affinity probes, were also incorporated into both subunits (Fasold et al., 1979).

The studies presented here indicate that $\varepsilon$-amino groups of lysine residues with similar reactivities in both tubulin subunits are involved in the microtubule assembly and that the carbamoylation of these residues prevents subunits from being incorporated into the growing microtubules.

We express our appreciation to Dr. Nicholas Seeds for his critical reading of the manuscript, and to Dr. Alphonse Krystosek for his helpful comments. The valuable help of Mrs. Isabel Maccioni and the technical assistance of Mr. Risnel Bustos are also acknowledged. This investigation was supported in part by Grant S-79-9 from Research Fund of Universidad Austral de Chile.

\section{References}

Allende, J. E., Seeds, N. W., Conway, T. W. \& Weissbach, H. W. (1967) Proc. Natl. Acad. Sci. U.S.A. 58, 1566-1573

Brodie, A., Babson, J. \& Reed, D. (1980) Biochem. Pharmacol. 29, 652-654

De Brabander, M. \& De May, J. (1980) Microtubules and Microtubule Inhibitors, pp. 1-576, Elsevier/NorthHolland, Amsterdam
Fasold, H., Mann, K. \& Giesel, M. (1979) Abstr. Int. Congr. Biochem. 11th p. 578

Galella, G. \& Smith, D. (1979) Abstr. Int. Congr. Biochem. 11th p. 579

Garner, M., Garner, W. \& Gurd, F. (1973) J. Biol. Chem. 248, 5451-5455

Gaskin, F., Cantor, C. \& Shelanski, M. (1974) J. Mol. Biol. 89, 737-758

Gaskin, F., Cantor, C. \& Shelanski, M. (1975) Ann. N.Y. Acad. Sci. 253, 133-146

Johnson, K. A. \& Borisy, G. G. (1975) in Molecules and Cell Movement (Inoue, S. \& Stephens, R., eds.), pp. 119-141, Raven Press, New York

Kuriyama, R. \& Sakai, H. (1974) J. Biochem. (Tokyo) 76, 651-654

Laemmli, U. K. (1970) Nature (London) 227, 680-685

Lee, Y., Houston, L. \& Himes, R. (1976) Biochem. Biophys. Res. Commun. 70, 50-57

Maccioni, R. B. \& Seeds, N. W. (1977a) Proc. Natl. Acad. Sci. U.S.A. 74, 462-466

Maccioni, R. B. \& Seeds, N. W. (1977b) J. Cell Biol. 75, 285a

Maccioni, R. B., Vera, J. C. \& Slebe, J. C. (1981a) in Molecular Approaches to Gene Expression and Protein Structure (Siddiqui, M. A. Q., Krauskopf, M. \& Weissbach, H., eds.), pp. 287-308, Academic Press, New York

Maccioni, R. B., Vera, J. C. \& Slebe, J. C. (1981b) Arch. Biochem. Biophys. 207, 248-255

Mann, K., Giesel, M., Fasold, H. \& Haase, W. (1978) FE BS Lett. 92, 45-48

Margolis, R. (1981) Proc. Natl. Acad. Sci. U.S.A. 78, 1586-1590

Margolis, R. \& Wilson, L. (1978) Cell 13, 1-8

Means, G. \& Feeney, R. (1971) Chemical Modification of Proteins, pp. 84-89, Holden-Day, San Francisco

Mellado, W., Slebe, J. \& Maccioni, R. B. (1980) Biochem. Int. 1, 584-590

Roberts, K. \& Hyams, J. S. (1979) Microtubules, pp. 1-530, Academic Press, London and New York

Schmidt, D. E. \& Westheimer, F. H. (1971) Biochemistry 10, 1249-1253

Slebe, J. \& Martinez-Carrion, M. (1976) J. Biol. Chem. 251, 5663-5669

Stark, G. (1965) Biochemistry 4, 1030-1066

Stark, G. (1972) Methods Enzymol. 25, 579-584

Timasheff, S. N. \& Grisham, L. (1980) Annu. Rev. Biochem. 49, 565-591

Veronese, F. M., Piszkiewicz, D. \& Smith, E. (1972) J. Biol. Chem. 247, 754-759

Weingarten, M., Lockwood, A., Hwo, S. \& Kirchner, M. (1975) Proc. Natl. Acad. Sci. U.S.A. 72, 1858-1862

Weisenberg, R., Borisy, G. \& Taylor, E. (1968) Biochemistry 7, 4466-4479 